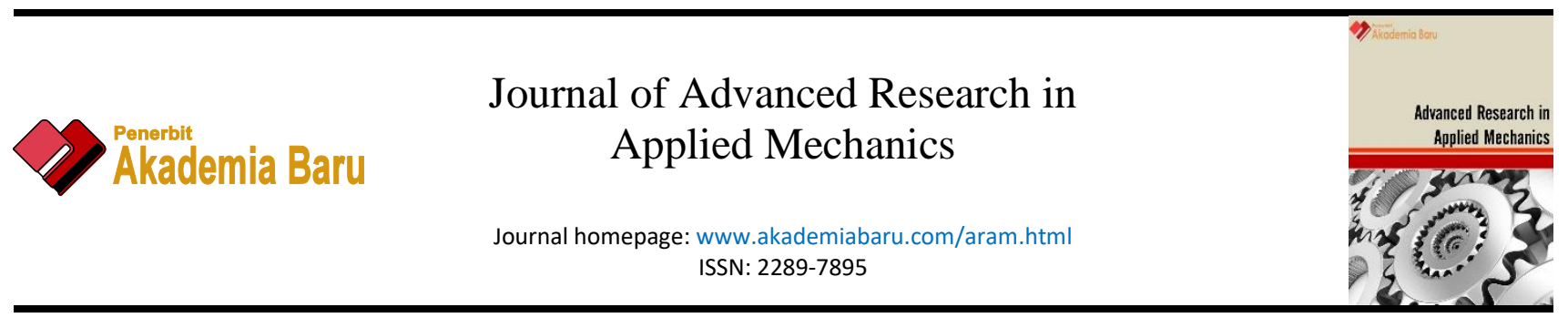

\title{
Smart Temperature Measurement System for Milling Process Application Based on MLX90614 Infrared Thermometer Sensor with Arduino
}

\author{
Agus Sudianto ${ }^{1,3}$, Zamberi Jamaludin ${ }^{1,}{ }^{*}$, Azrul Azwan Abdul Rahman², Sentot Novianto ${ }^{4}$, Fajar \\ Muharrom $^{5}$ \\ 1 Smart Factory System - Centre of Smart System and Innovative Design, Fakulti Kejuteraan Pembuatan, Universiti Teknikal Malaysia Melaka, \\ Hang Tuah Jaya, 76100 Durian Tunggal, Melaka, Malaysia \\ 2 Advanced Manufacturing Center, Universiti Teknikal Malaysia Melaka, Hang Tuah Jaya, 76100 Durian Tunggal, Melaka, Malaysia \\ 3 Mechanical Engineering Department, STT YBS Internasional, Jln. Pasar Wetan, Kompleks Mayasari Plasa, 46123 Kota Tasikmalaya, West Java, \\ Indonesia \\ 4 Department of Mechanical Engineering, Faculty of Industrial Technology, Universitas Trisakti, Jakarta 16424, Indonesia \\ 5 Faculty of Ingenieurwissenschaften, Universitaet Duisburg-Essen, Forsthausweg 2 Duisburg 47057, North Rheine Westphalia, Germany
}

\section{ABSTRACT}

Temperature measurement system on the manufacturing process of parts has become a smart measurement. This is applied in non-conventional machining processes and on the computer numerical control (CNC) machine. This system measures the temperature of the product during the machining process. Currently, Infrared Fusion using the Fluke Ti400 has been employing to measure temperature during the machining process. This measurement system is smart, only the temperature measurement data cannot link to the computer when the temperature measurement takes place. For this reason, the author conducts research on the measurement of the temperature of the CNC milling machining process on aluminum alloy material using the MLX90614 Infrared Thermometer Sensor which is operated through Arduino. Through this tool, temperature measurement data is directly entered into the computer because the MLX90614 Infrared Thermometer Sensor is compatible and linked to Microsoft Exel through Arduino. Arduino is an electronic device of microelectronic technology widely use with the microcontroller in applications based on the Internet of Things (IOT) in areas of health, agriculture, traffic monitoring, robotics and automation. However, in the field of machining, the use of Arduino based technology is still very limited. This paper presents a work-study on the performance of Arduino based temperature measuring system for milling process applications. Here, Arduino based temperature measuring system was proposed using an MLX90614 Infrared Thermometer sensor to capture workpiece temperature during machining processes where the measurement data were compared with Infrared Fusion of Fluke Ti400. Aluminum Alloy (AA6041) was used as the machining subject in this experiment. Measurement results from both devices showed similar accuracy level with a deviation of only around $\pm 2 \mathrm{oC}$. The MLX90614 Infrared Thermometer sensor that is Arduino compatible was designed as the temperature measuring system in the dry milling process for temperature measurement purpose. Temperature measurement using the MLX90614 Infrared Thermometer sensor becomes smart because this device is compatible and linked to Microsoft Excel. This makes it convenient for retrieval of experimental results.

Keywords:

Milling process, Arduino MLX90614

infrared thermometer, fluke Ti400

infrared fusion, smart measurement

Copyright @ 2020 PENERBIT AKADEMIA BARU - All rights reserved

\footnotetext{
* Corresponding author.

E-mail address: zamberi@utem.edu.my
}

https://doi.org/10.37934/aram.72.1.1024 


\section{Introduction}

The temperature of the cutting process in manufacturing production is very important. This will cause changes in product behavior after completion of work. We need to pay attention when making finished products, to concern regarding temperature rise due to the impact of the machining process [1] that has negative consequences on the machining characteristic such as surface roughness especially that of Aluminum-based materials [2]. The cutting tool performance is certainly dependent on the form stability of the geometry tools, the effectiveness working and thermal conductivity of the tool against the material processes that are either ferrous or non-ferrous. A temperature measuring system would monitor any temperature during the machining process. Through Information and Communication Technology (ICT) such tools as cloud computing including robotic and automation, Internet of Things (IOT) and machine learning have emerged as a possible solution for the temperature monitoring system of a machining process. These technologies make the manufacturing industry smart and capable of addressing current changes, such as improved quality, increasingly customized requirements and reduced time, but certainly, the product would being affordable price [3].

The MLX90614 infrared thermometer is a contactless temperature sensor module for Arduino compatible device. An infrared thermometer works to measure the object temperature by the infrared radiation in the form of an electromagnetic wave through the light emitted on the object [4]. MLX90614 is a powerful infrared sensing device with a very low noise amplifier with a 17 bit ADC. It utilizes non-contact temperature sensing to collect the temperature info without touching any surface of the object. It enables to obtain the measurement of high accuracy and resolution. It was calibrated with a digital System Management Bus (SMBus) from the factory in wide temperature ranges: $-40{ }^{\circ} \mathrm{C}$ to $125^{\circ} \mathrm{C}$ for the ambient temperature and $-70^{\circ} \mathrm{C}$ to $380^{\circ} \mathrm{C}$ for the object temperature with being standard accuracy of $\pm 0.5{ }^{\circ} \mathrm{C}$ around room temperatures. An accuracy of $\pm 0.2{ }^{\circ} \mathrm{C}$ in a limited temperature range around the human body temperature has been offered to a special version for medical applications exist [5].

Arduino possesses the technology of high-speed digital signal processing, minor cable wiring in communicating, then absolutely provides people with a convenient, rapid, effective and efficient method. It is determining the MLX 90614 Infrared Thermometer that linked to Microsoft Excel for retrieval temperature data due to the impact of milling process through temperature sensor module with Arduino making it more convenient in analyzing the data. To-date, many researchers have performed temperature data retrieval utilizing infrared Fluke Ti400 sensor.

In other fields, Arduino has been widely used in various fields of medicine [6] such as to develop heart rate and body temperature monitoring system [7], diseases of heart disease, diabetes etc [8]. In the field of power systems such as plantations thermal generator [9] and crop health monitoring [10]. Also in household devices [11, 12].

For this reason, researchers can apply knowledge of microcontrollers with various loT-based sensors through the Arduino program. In the field of manufacturing, the researchers will respond in the use of microcontroller devices, especially in the machining process to utilize microcontrollers that can be compatible and linked to Microsoft excel to take the experiment data becoming smarter. Therefore, the author employs infrared sensors of MLX90614 with Arduino can determine the temperature measuring system on a milling process application would be better.

This paper arranges neatly as follows; Explanation MLX90614 is as an introduction, section 2 presents regarding materials and methods include measurement and methodology in explaining the MLX90614 Infrared Thermometer based on Arduino that Compared by Fluke Ti400 in measuring the temperature of AA6041. In Section 3, to discuss the result data of temperature measurement then 
analysis of it by comparing the MLX90614 Infrared Thermometer toward Fluke Ti400 infrared fusion. The author made the conclusion in Section 4.

\section{The Material and Method}

The working principle of an infrared thermometer is based on black body radiation, with any material at temperatures above absolute zero having molecules moving in it. Molecules move faster when the temperature is higher. Molecules emit infrared radiation when they move, and emit more radiation, including visible light, when they become hotter. Elucidated [13] regarded the basic measurement equation for Infrared Thermometry as:

$S(T)=\varepsilon S\left(T_{S U R F}\right)+(1-\varepsilon) S\left(T_{B G}\right)$

Equation (1) elucidates both of the background temperature (TBG) and the temperature of the object being measured (TSURF) has been influenced by the signal for any measurement. While SakumaHattori Equation in equation (2) at below revealed the problematic almost happened for the usage of handheld industrial type instruments like handphones. These instruments did not provide the $A$, $B$ and $C$ constants as in their equation.

$L(\lambda, T)=\frac{C_{1 L}}{\lambda^{5}\left[\exp \left(\frac{c_{2}}{\lambda T}\right)-1\right]}$

Also, the Wien's Displacement, Planck and Stefan-Boltzmann [14] equation describe the peak wavelength for a given temperature. The wavelength was influenced by temperature as is shown in fig. 1 Wien's Displacement Law:

$\lambda_{\max } T=c_{3}$

Planck's Law:

$S=\frac{C}{\exp \left(\frac{c_{2}}{A T+B}\right)}$

Stefan-Boltzmann Law:

$M=\sigma T^{4}=\pi \int_{0}^{\infty} L(\lambda, T) d \lambda$

For all the above equations:

$\mathrm{S} \quad=$ readout radiance measurement from the radiometric reference

$\mathrm{T}=$ temperature

TSURF = temperature of the object being measured

TBG = background temperature

$\lambda \quad=$ wavelength

$\varepsilon \quad=$ emissivity

$A, B, C=$ calibration constants from radiometric reference

$\mathrm{M} \quad=$ electromagnetic spectrum

$\sigma \quad=$ energy 
$\mathrm{L}=$ = spectral radiance

Figure 1 shows the relationship between Planck's Law and Wien's Displacement Law. Note carefully that the peak energy for the Sun is around $0.5 \mu \mathrm{m}$ while at room temperature of $23^{\circ} \mathrm{C}$. It is below $10 \mu \mathrm{m}$.

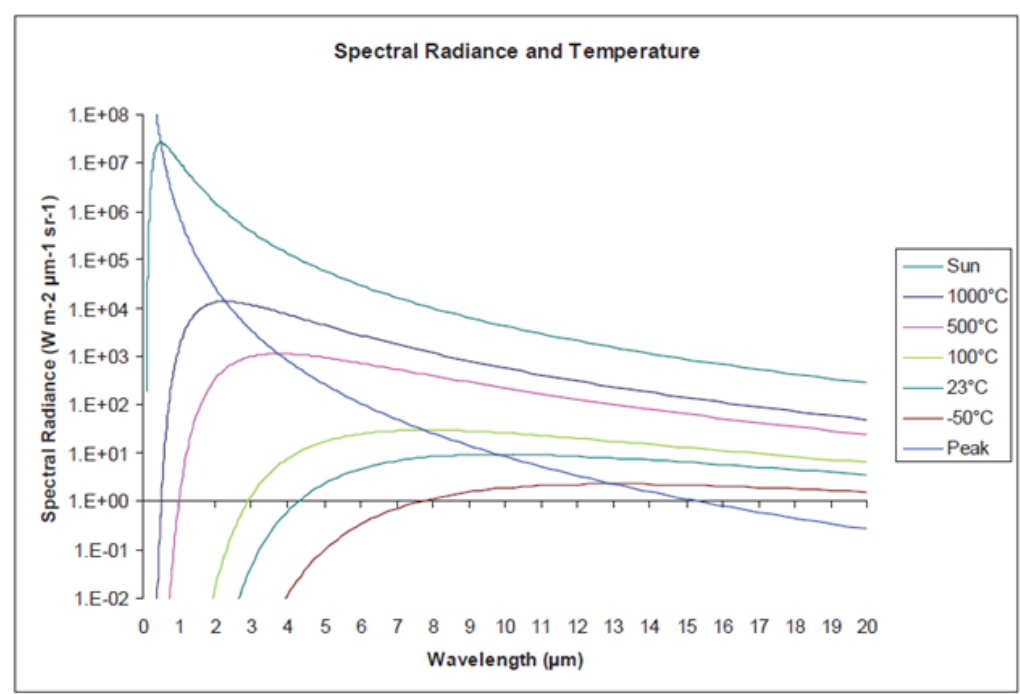

Fig. 1. The relation between Planck's Law and Wien's Displacement Law [14]

Three other issues that require consideration of infrared thermometer treatment are:

a. Expose to thermal shocks.

b. Measurement conditions.

c. Influence of optical hygiene.

\subsection{Measurements}

In this part presents the compared MLX90614 to the FLUKE Ti400, explained in the subchapter.

\subsubsection{MLX90614 Infrared Contactless Thermometer}

The MLX90614 is shown in fig. 2 could get a temperature reading of an object without coming into contact with the object using both emissivity and radiation as a means of measurement. Emissivity is a coefficient that shows how well an object emits infrared radiation compared to a theoretically perfect black body producer. This radiation is used by MLX90614 to calculate the object temperatures. During manufacturing, MLX90614 is calibrated with the black matter with an emissivity $=99.9 \%$ which is considered to be $E=1$ and details the specifications of MLX90614 infrared thermometer in Table 1. 
Table 1

Detail description of MLX90614 Infrared Thermometer specification

\begin{tabular}{ccc}
\hline Attribute & Value & Unit \\
\hline Ambient Temperature Range & -40 to 125 & ${ }^{\circ} \mathrm{C}$ \\
Object Temperature Range & -70 to 380 & ${ }^{\circ} \mathrm{C}$ \\
Detector Resolution & 0.02 & ${ }^{\circ} \mathrm{C}$ \\
Versions & Single and dual-zone & \\
Application & Arduino, SMBus compatible digital interface \\
Model Number & MLX90614 & ${ }^{\circ} \mathrm{C}$ \\
Measurement Resolution & 0.02 & ${ }^{\circ} \mathrm{C}$ \\
Best Temperature Measurement Accuracy & 0.5 & $\mathrm{~V}$ \\
Focus Type & Manual & $\mathrm{Cm}$ \\
Version & 3 and 5 & $\mathrm{gram}$ \\
Display Size & LCD $16 \times 2$ & $<250$ \\
Weight & Affordable & \\
Price & &
\end{tabular}

The MLX90614 Infrared Thermometer needs to be connected to the Arduino. Setting up for the connection of the MLX90614 sensor is shown in fig. 2-4 that consist of:
a. Arduino
b. Character LCD $16 \times 2$
c. MLX90614
d. LCD Shield

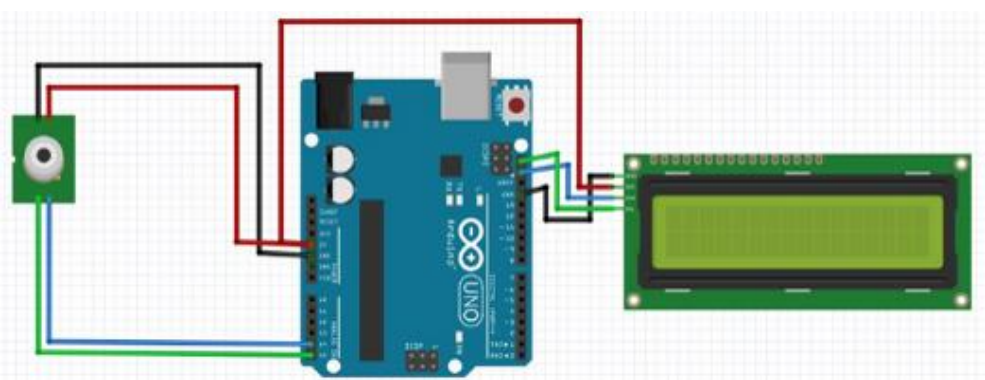

Fig. 2. The MLX90614 Infrared thermometer connected to the Arduino and LED display [5]

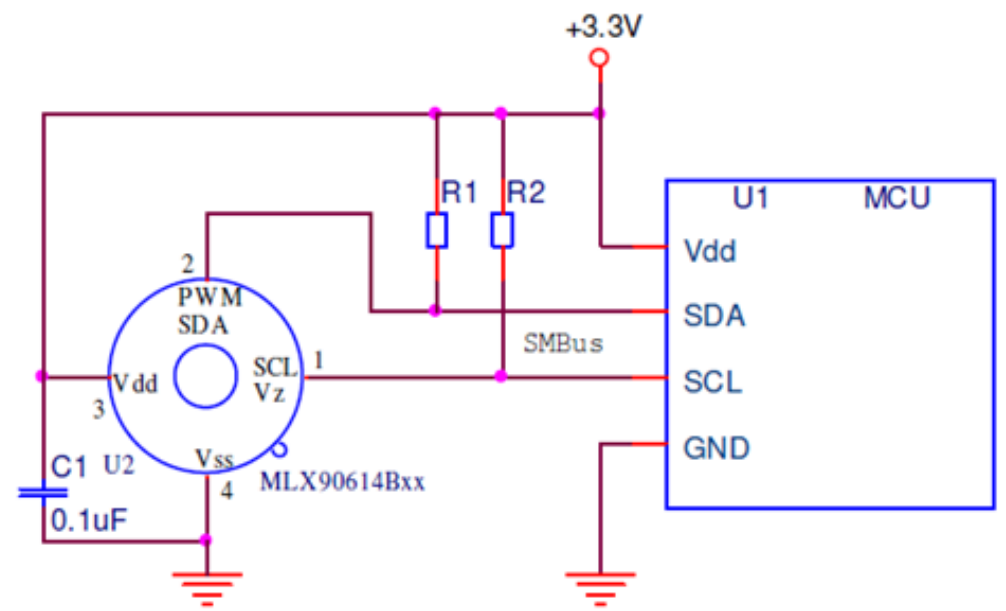

Fig. 3. The MLX90614 connection to SM Bus [5] 


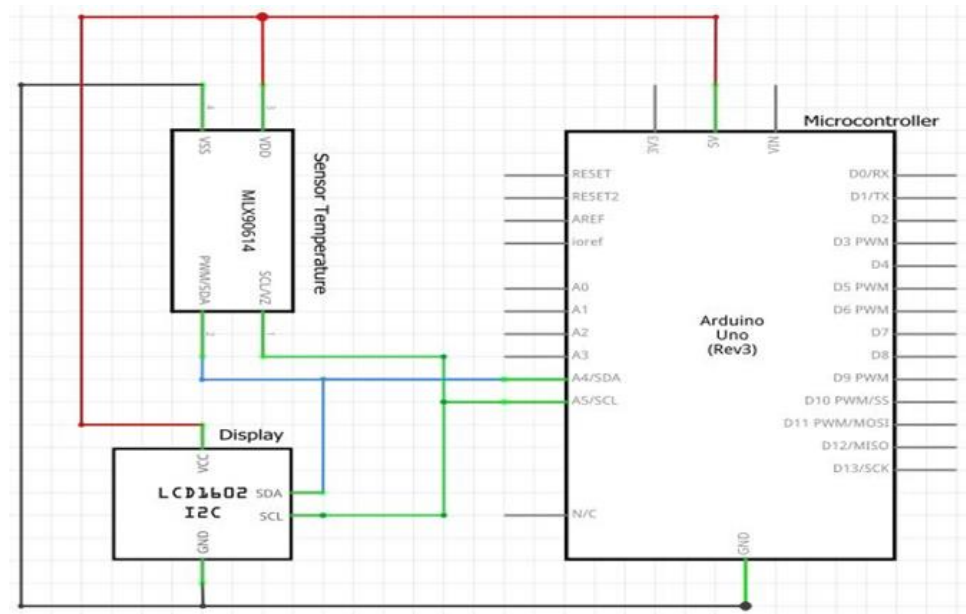

Fig. 4. Schematic of the MLX90614 infrared thermometer

In order to communicate with the Arduino unit, programming codes are desired. The followings are the temperature measurement programming codes for the MLX90614 infrared thermometer compatible to Arduino:

\#include <Wire.h>

\#include <Adafruit_MLX90614.h>

\#include <LiquidCrystal_I2C.h>

LiquidCrystal_I2C Icd(0x27, 16, 2);

Adafruit_MLX90614 mlx= Adafruit_MLX90614();

void setup() \{

Serial.begin(9600);

Icd.begin();

Icd.backlight();

mlx.begin();

Serial.printIn("CLEARDATA"); // to clear the data in exel

Serial.printIn("LABEL, Time Stamp, Temperature"); // to input the name in every column

\}

void loop() \{

//Serial.println();

//Serial.print("Ambient = "); Serial.print(mlx.readAmbientTempC()); //Print Temperature ambient in Serial Monitor

//Serial.print("*CltObject = "); Serial.print(mlx.readObjectTempC()); Serial.printIn("*C"); //Print

Temperature object in Serial Monitor

Icd.clear();

Icd.setCursor(0,0);

Icd.print("Temp: ");

Icd.print(mlx.readObjectTempC());

Serial.print("DATA,TIME,"); // to deliver values to the exel

Serial.print(mlx.readObjectTempC());

$\operatorname{delay}(1000)$;

\}

The above program explains that the actual temperature measurement in Celsius degree, read on the LCD screen. Simultaneously the data is delivered every 1000 milliseconds into Microsoft Excel. 


\subsubsection{Fluke Ti400 Infrared Fusion Temperature Measurement}

The detailed data description in table 2 below is a specification of the Fluke Ti400 infrared fusion.

Table 2

Detail description of Fluke Ti400 infrared fusion specification

\begin{tabular}{ccc}
\hline Attribute & Value & Unit \\
\hline Temperature Measurement Range & -20 to +1200 & ${ }^{\circ} \mathrm{C}$ \\
Detector Resolution & $320 \times 240$ & pixel \\
Display Resolution & $640 \times 480$ & pixel \\
Application & Thermography & \\
Model Number & Tl400 & \\
Thermal Sensitivity & 0.05 & ${ }^{\circ} \mathrm{C}$ \\
Best Temperature Measurement Accuracy & \pm 2 & ${ }^{\circ} \mathrm{C}$ \\
Focus Type & Automatic, Manual & \\
Refresh Rate & 9 & $\mathrm{~Hz}$ \\
Minimum Focus Distance & 15 & $\mathrm{~cm}$ \\
Display Size & 3.5 & $\mathrm{inch}$ \\
Weight & 1 & $\mathrm{~kg}$ \\
\hline
\end{tabular}

\subsection{Methodology}

Figure 5 illustrates the methodology applied for this research work. The first part of the experiment consists of the sensor temperature readings validation. Here, the temperature measurements of MLX90614 infrared thermometer were compared with that of the Fluke Ti400 infrared fusion temperature sensor.

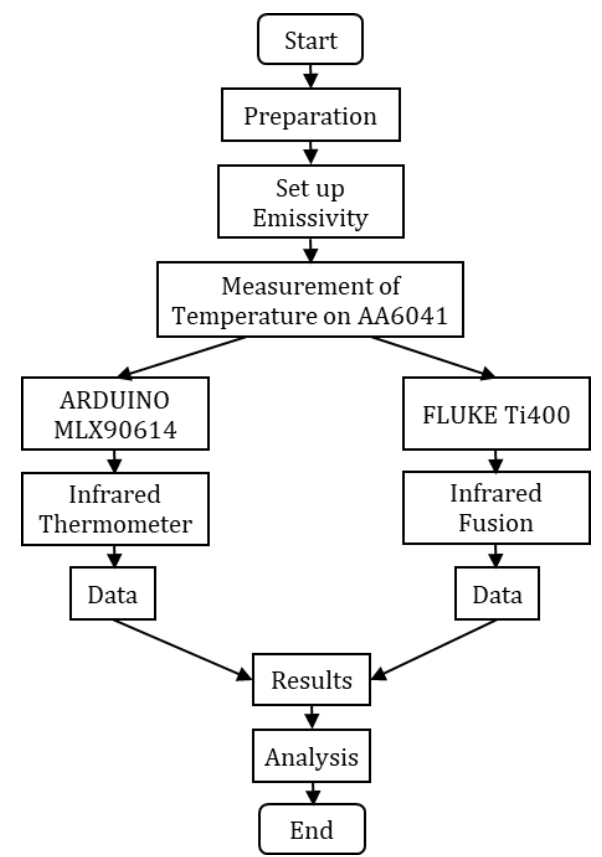

Fig. 5. Temperature validation measurement 


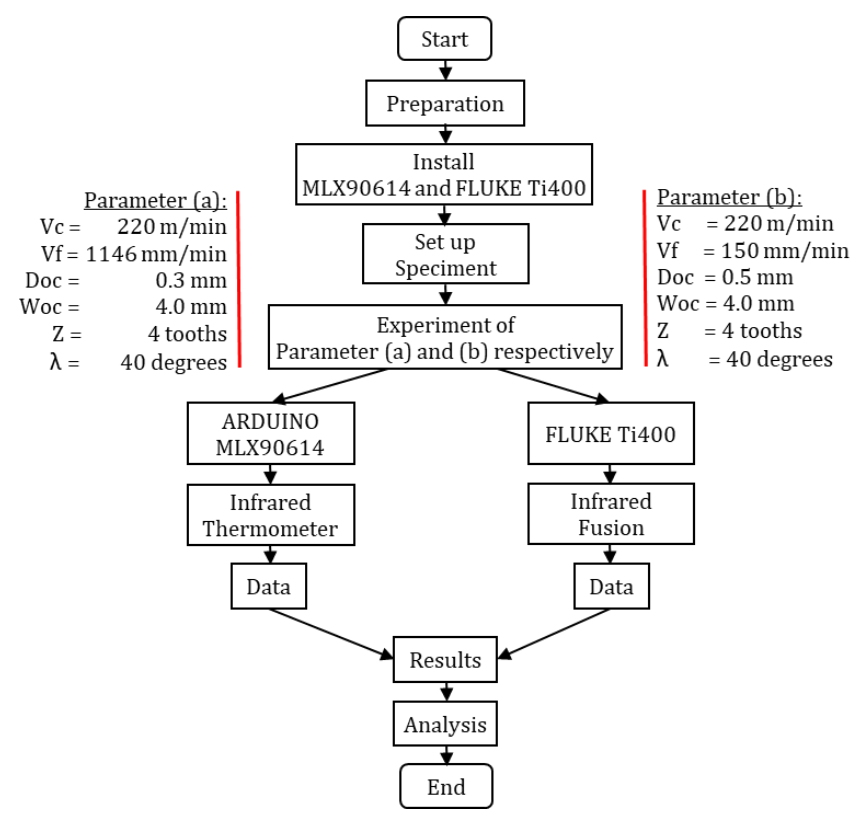

Fig. 6. Milling process temperature measurement

The work starts with sample preparation including a heater for heating specimen AA6041, two measurement devices and a personal computer (PC) or laptop to store the temperature data. Temperature measurements were recorded simultaneously using MLX90614 and Ti400 by adjusting the emissivity values of both measurement units. Next, the design of the temperature model was constructed to conduct an experiment and obtaining the data set of heat temperature as many as nine temperature models. Finally, the measured data were analyzed. This figure was applied to seem figure 9.

Figure 6 describes the experiment flow on AA6041, which involves the machining parameters such as cutting speed, feeding speed, depth of cut, width of cut, flute and tool angle. The application of this flow seems at the fig. 10.

\subsubsection{Measurement Preparation}

The followings illustrate measurement preparations that were performed using the MLX90614 Infrared Thermometer with AA6041 specimen. The steps consisted of:

a. Specimen AA6041 as shown in fig. 7 was heated to nine different temperatures and data recorded using MLX90614 and Fluke three times continuously, employed the heat from a temperature of $60{ }^{\circ} \mathrm{C}$ to $225^{\circ} \mathrm{C}$

b.

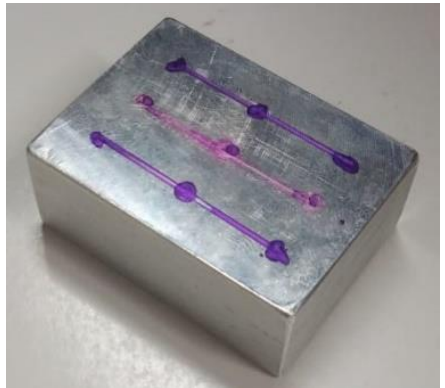

Fig. 7. Specimen AA6041, size of $50 \times 38 \times 20$ in $\mathrm{mm}$. 
b. MLX 90614 infrared thermometer as in fig. 8 (a) is compatible to Arduino and was linked to Microsoft Excel for data recording.

c. The infrared fusion of Fluke Ti400 $9 \mathrm{~Hz}$ as shown in fig. 8 (b) recorded the temperature in graphical form and videos with temperature measurement range between $-20^{\circ} \mathrm{C}$ to $1200^{\circ} \mathrm{C}$ with an accuracy of $\pm 2{ }^{\circ} \mathrm{C}$.

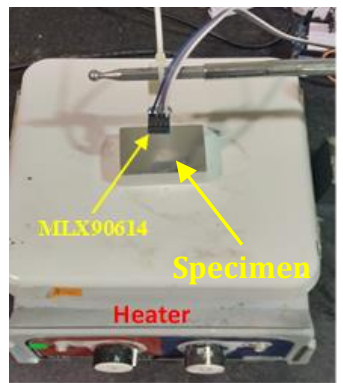

(a)

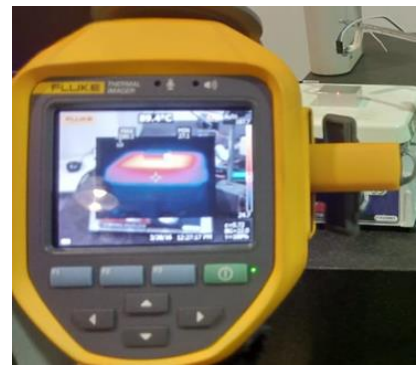

(b)

Fig. 8 (a). Temperature measurement using MLX90614 infrared thermometer, (b). Temperature measurement using infrared fusion Fluke Ti400

\subsubsection{Experimental design for Temperature Measurement}

This first part of this section describes the experimental design set up for validating the temperature measurement of MLX90614 against Fluke Ti400. In the second part, temperature measurements were recorded on the milling machining process.

\subsubsection{Validation for Temperature measurement on AA6041}

A total of nine sets of temperature measurements were recorded on the AA6041 object whereby these measurements were repeated three times. The measurements were performed gradually from low temperatures of $68{ }^{\circ} \mathrm{C}$ to high temperatures of close to $220^{\circ} \mathrm{C}$. Fig. 9 shows the experimental measurement setup employing (a) MLX90614 and (b) Fluke Ti400.

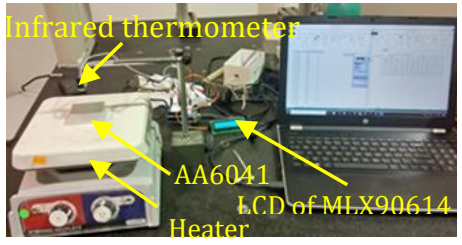

(a)

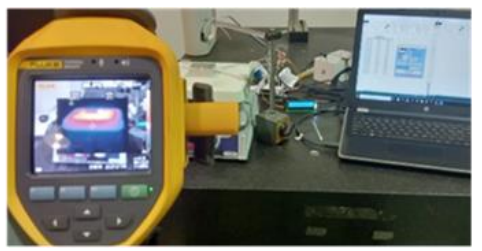

(b)

Fig. 9 (a). The temperature measurement by MLX90614

(b). The temperature measurement by Fluke Ti400

A similar experimental setup was applied by [14] who monitored the steel plate temperatures employing an MLX90614 infrared sensor with Arduino with the help of the RF433Mhz module. Meanwhile, [15] have applied Arduino IDE based in CCS language CCS as a thermal monitoring system employing low-cost MEGA flat form. 


\subsubsection{Measurement of Temperature on AA6041 in Milling Process}

Fig. 10 below shows the temperature measurement on AA6041 material in the milling process. Temperature data by the MLX90614 were recorded in a laptop through Arduino and linked to Microsoft Excel.

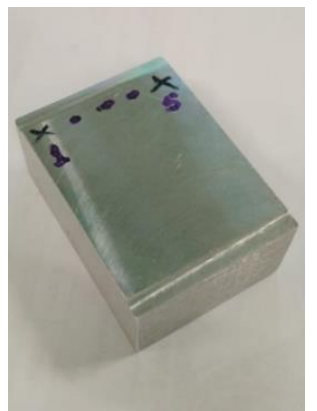

(a)

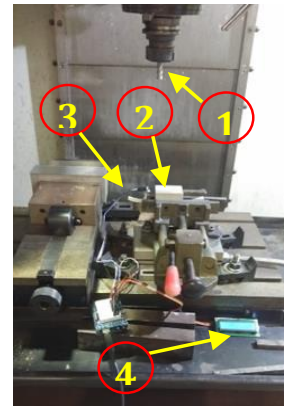

(b)

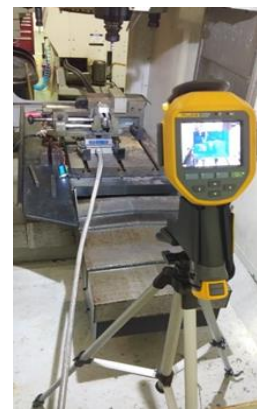

(c)

Fig. 10. (a). Specimen milling, (b). Take up the temperature by MLX90614, (c) Take up the temperature by fluke Ti400

Remark in fig. 10 (b). Denotes that (1) is a cutting tool HPMT S42 1000 072, (2) is an AA6041 specimen, (3) is an infrared thermometer (4) is a screen LCD of MLX90614.

The temperature data measured using Fluke was stored in the Fluke memory in the form of images or videos. Fig. 11 (a) shows the experimental setup used. Paying attention at fig. 11 (b), shown at the left side (yellow circle) and right side (red circle). The Left and right side explain that the side has obtained milling process for the measurement- 1 and measurement- 2 parameters respectively.

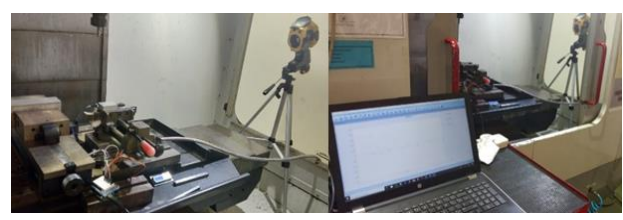

(a)

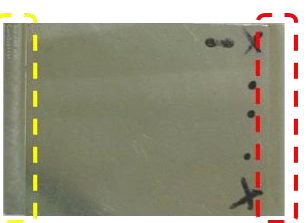

(b)

Fig. 11. (a). Measuring temperatures, (b). A specimen that derived the milling process.

\section{Results}

This section presents experimental results of the two types of experiments performed; firstly the temperature measurement validation and secondly the milling process heat temperature measurement itself.

\subsection{Experiment Result}

The measurement consists of three processes in which each process consists of nine times of measurement on the AA6041 specimen. 


\subsubsection{Temperature Measurement}

Measurements of the heat temperature in AA6041 were carried out in nine measurement processes in which each process consists of three measurements as identified in the previous fig. 6 . The graphical representation of the data is presented in fig. 12 with MLX90614 (blue) and Fluke Ti400 (green) displaying an increasing trend where the deviation line shown at 0.1 scales.

To determine two measurements that are the same or different, usually using statistical analysis. Due to the properties of the two measurements are not different, the author measures the temperature of the measurement results based only on the average value from nine experiment data as shown in table 3.

Table 3

Temperature measurement (in ${ }^{\circ} \mathrm{C}$ ) on AA6014 by MLX90614 and Fluke Ti4000 with 0.72 emissivity.

\begin{tabular}{|c|c|c|c|c|c|c|c|c|c|}
\hline \multirow{2}{*}{ No. } & \multicolumn{3}{|c|}{ MLX90614 } & \multicolumn{3}{|c|}{ FLUKE Ti400 } & \multirow{2}{*}{$\begin{array}{c}\text { MLX90614 } \\
\text { Average }\end{array}$} & \multirow{2}{*}{$\begin{array}{c}\text { FLUKE } \\
\text { Average }\end{array}$} & \multirow{2}{*}{ Deviation } \\
\hline & 1 & 2 & 3 & 1 & 2 & 3 & & & \\
\hline 1 & 68.14 & 68.98 & 70.92 & 68.10 & 68.30 & 70.90 & 69.35 & 69.10 & 0.25 \\
\hline 2 & 100.34 & 101.40 & 106.00 & 100.70 & 101.70 & 106.40 & 102.58 & 102.93 & 0.35 \\
\hline 3 & 126.30 & 125.42 & 125.00 & 126.70 & 125.60 & 125.80 & 125.57 & 126.03 & 0.46 \\
\hline 4 & 134.70 & 138.50 & 137.32 & 134.50 & 138.30 & 136.30 & 136.84 & 136.37 & 0.47 \\
\hline 5 & 153.50 & 157.70 & 160.14 & 153.00 & 156.40 & 160.50 & 157.11 & 156.63 & 0.48 \\
\hline 6 & 173.42 & 177.70 & 183.32 & 173.40 & 177.50 & 183.80 & 178.15 & 178.23 & 0.09 \\
\hline 7 & 190.60 & 191.60 & 190.70 & 190.50 & 191.50 & 190.10 & 190.97 & 190.70 & 0.27 \\
\hline 8 & 211.40 & 212.20 & 216.22 & 211.40 & 212.10 & 216.90 & 213.27 & 213.47 & 0.19 \\
\hline 9 & 216.40 & 222.58 & 221.60 & 216.30 & 222.10 & 221.50 & 220.19 & 219.97 & 0.23 \\
\hline
\end{tabular}

The results above show that temperature measurements of MLX90641 were closely similar to the temperature measurement results of Fluke Ti400. The average accuracy values of every measurement were $\pm 2{ }^{\circ} \mathrm{C}$. On the bottom graph in fig. 12, denotes the values belong MLX90614 (blue graph) and Fluke Ti400 (green graph) increases like regularly, while the deviation line shown clear with 0.1 scales. While the red line is the deviation line, looks significant because the range of the scale is very small.

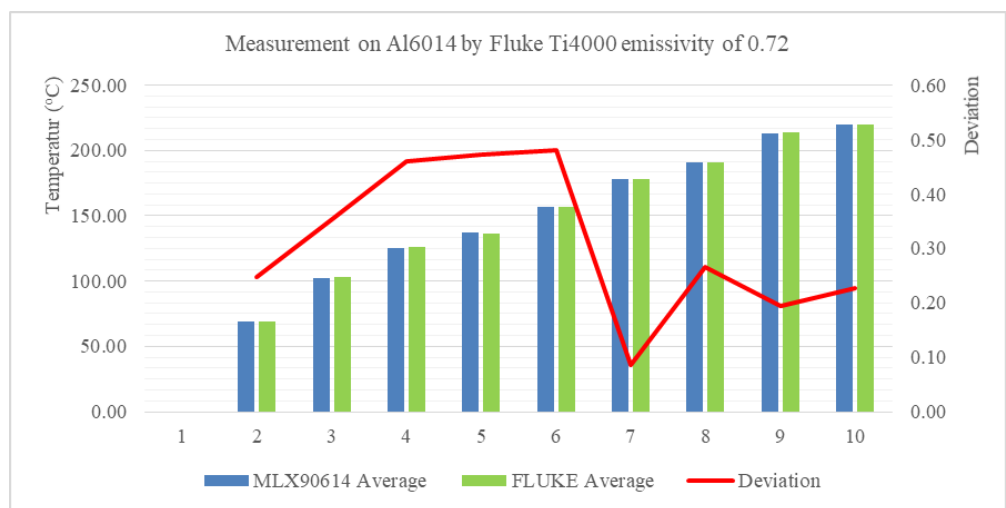

Fig. 12. Graph of the average measurement result between MLX90614 and Fluke Ti400 


\subsubsection{Smart Temperature Measurement on AA6041 in Milling Process}

Two different sets of milling process parameters were conducted. Fig. 11 (b) shown the left side (yellow circle) and right side (red circle) of the specimen. The left side refers to the milling process for measurement-1 parameters while the right side refers to the milling process for the measurement-2 parameters.

Table 4

Cutting parameters for Measurement-1

\begin{tabular}{ccc}
\hline Parameters & Values & Units \\
\hline Vc & $220(7006)$ & $\mathrm{m} / \mathrm{min}(\mathrm{rpm})$ \\
Vf & $1146(\mathrm{fz}=0.041)$ & $\mathrm{mm} / \mathrm{min}(\mathrm{mm} /$ tooth $)$ \\
Doc & 0.3 & $\mathrm{~mm}$ \\
Woc & 4.0 & $\mathrm{~mm}$ \\
$\mathrm{Z}$ & 4 & tooth \\
$\lambda$ & 40 & degrees \\
\hline
\end{tabular}

Table 5

Cutting parameters for Measurement-2

\begin{tabular}{ccc}
\hline Parameters & Values & Units \\
\hline Vc & $220(7006)$ & $\mathrm{m} / \mathrm{min}(\mathrm{rpm})$ \\
Vf & $150(\mathrm{fz}=0.0053)$ & $\mathrm{mm} / \mathrm{min}(\mathrm{mm} /$ tooth $)$ \\
Doc & 0.5 & $\mathrm{~mm}$ \\
Woc & 4.0 & $\mathrm{~mm}$ \\
$\mathrm{Z}$ & 4 & tooth \\
$\lambda$ & 40 & degrees \\
\hline
\end{tabular}

Tables 4 and 5 are a list of the machining parameters selected. Both parameters difference in feeding speed and depth of cut merely. The result of the experiment data can be seen in Table 6 which lists the temperature measurement results obtained during the different milling processes.

With proven of temperature measurement by applying in milling process on AA6041 through the measurement by MLX90614 (table 6) and Fluke Ti400 (fig. 13) to make more proofed that MLX90614 is capable and to be recommended to be employed as a temperature measurement in machining. By the Explanation above result denotes the MLX90614 to be confident to be utilized as a temperature measurement device in machining with the dry condition. The author derives a recommendation to the researchers to utilize MLX90614 infrared thermometer with Arduino compatible and linked to Microsoft Excel is a temperature measurement device on the machined product in manufacturing production.

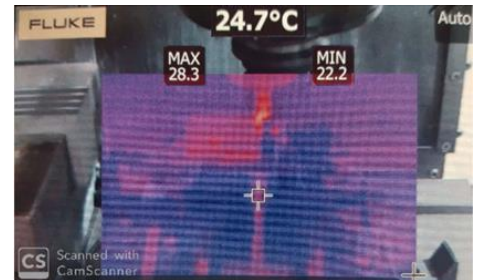

(a)

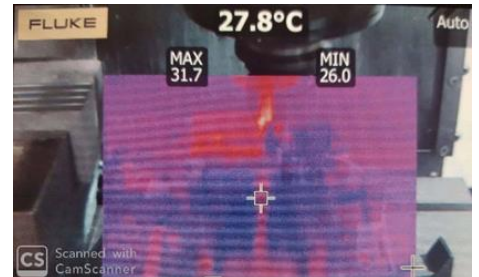

(b)

Fig. 13 (a). Measurement-1 by Infrared Fusion (b). Measurement2 by Infrared Fusion 
Table 6

Measurement by MLX90614

\begin{tabular}{|c|c|c|c|}
\hline \multicolumn{2}{|c|}{ (a) Measurement-1 } & \multicolumn{2}{|c|}{ (b) Measurement-2 } \\
\hline Time Stamp & $\begin{array}{c}\text { Temperature } \\
\text { Value }\left({ }^{\circ} \mathrm{C}\right)\end{array}$ & Time Stamp & $\begin{array}{c}\text { Temperature } \\
\text { Value }\left({ }^{\circ} \mathrm{C}\right)\end{array}$ \\
\hline 1 & 23.74 & 1 & 26.68 \\
\hline 2 & 23.76 & 5 & 26.76 \\
\hline 3 & 23.76 & 6 & 26.82 \\
\hline 4 & 23.92 & 7 & 26.86 \\
\hline 5 & 23.88 & 8 & 26.92 \\
\hline 6 & 23.98 & 9 & 27.00 \\
\hline 7 & 23.86 & 10 & 27.04 \\
\hline 8 & 23.94 & 11 & 27.06 \\
\hline 9 & 24.00 & 12 & 27.18 \\
\hline 10 & 24.10 & 13 & 27.40 \\
\hline 11 & 24.04 & 14 & 27.52 \\
\hline 12 & 24.00 & 15 & 27.66 \\
\hline 13 & 24.06 & 16 & 27.82 \\
\hline 14 & 24.24 & 17 & 27.82 \\
\hline 15 & 24.22 & 18 & 27.88 \\
\hline 16 & 24.40 & 19 & 27.88 \\
\hline 17 & 24.58 & 20 & 27.72 \\
\hline 18 & 24.66 & 21 & 27.60 \\
\hline 19 & 24.60 & 22 & 27.48 \\
\hline 20 & 24.72 & 23 & 27.30 \\
\hline 21 & 24.58 & 24 & 27.24 \\
\hline 22 & 24.52 & 25 & 27.06 \\
\hline 23 & 24.30 & 26 & 27.00 \\
\hline 24 & 24.24 & 27 & 26.98 \\
\hline 25 & 24.18 & 28 & 26.98 \\
\hline 26 & 24.22 & 29 & 26.92 \\
\hline 27 & 24.10 & 30 & 26.94 \\
\hline 28 & 24.06 & 31 & 26.92 \\
\hline 29 & 23.98 & 32 & 26.86 \\
\hline 30 & 23.88 & 33 & 26.86 \\
\hline
\end{tabular}

3.2 Temperature measurement Analysis of MLX90614 Infrared Thermometer based on Arduino and Fluke Ti400

In the first part of the experiment, the temperature measurement of both MLX90614 and Fluke Ti400 was validated for accuracy. Results have shown that near-identical readings were obtained by both sensory units. For example, in the first measurement, the average temperature recorded was $69.35^{\circ} \mathrm{C}$ and $69.10^{\circ} \mathrm{C}$ by MLX90614 and Fluke Ti400 respectively while on the ninth measurement, the average temperature was $220.19{ }^{\circ} \mathrm{C}$ and $219.97{ }^{\circ} \mathrm{C}$. This shows a temperature deviation of only.

For the second part, the specimen AA6041 milling temperature results of two processes indicate readings of $24.72{ }^{\circ} \mathrm{C}$ and $27.88^{\circ} \mathrm{C}$ using MLX90614 while results of $24.7^{\circ} \mathrm{C}$ and $27.8^{\circ} \mathrm{C}$ were recorded by Fluke Ti400. A near-identical temperature measurement results were obtained in both cases.

This indicates that the MLX90614 Infrared Thermometer compatible with Arduino with link to Microsoft Excel was successfully designed and validated as a smart temperature measurement system for milling process. The advantage of this system is that it enables automatic temperature measurements of the $\mathrm{CNC}$ milling process of up to $350{ }^{\circ} \mathrm{C}$. 


\section{Conclusions}

This paper presents the development of a smart milling process temperature measurement system based on MLX90614 Infrared Thermometer coupled with Arduino microcontroller. The smart measurement system successfully recorded accurate measurement results on AA6041 specimen with as much as nine times with each time as many as three processes. The measurement results were validated for its accuracy against the Infrared Fusion Fluke Ti400 temperature sensor. The deviation data values of it were very small. It ranges at 0.09 to 0.48 of the deviation scale.

The full design and tested MLX90614 Infrared Thermometer compatible with Arduino form a temperature measurement tool that is permissible and feasible to be employed by researchers in the field of manufacturing engineering. An automatic temperature measurement system with simultaneous data logging serves as a beneficial tool to many researchers in the field of cutting tools for measuring the temperature operation.

Infrared Thermometer can measure the temperature in the machined products due to the impact of the milling process. Previously, this is only possible as demonstrated widely in literature for application in education, control health, agriculture, traffics and many more. However, to the best knowledge of the authors, no such loT-based system has been designed and applied for automatic measurement and recording of temperature in the milling process.

MLX90614 Infrared Thermometer is a smart, compact, and compatible device with Arduino that can be linked to Microsoft Excel and is very convenient to use in measuring the temperature product on machining operation in manufacturing production. This is proven after comparing the measurement result between Arduino toward Fluk. The data of measuring temperature results through MLX90614 Infrared Thermometer using Arduino is smarter. Therefore, this measurement is a smart temperature measurement system for the machining process in this case for the milling process.

\section{Acknowledgement}

The authors would like to thank the Faculty of Manufacturing Engineering, Universiti Teknikal Malaysia Melaka (UTeM) for the facilities provided and Sekolah Tinggi Teknologi YBS Internasional for the support given.

\section{References}

[1] Kasim, M. S., M. S. A. Hafiz, J. A. Ghani, C. H. C. Haron, R. Izamshah, S. A. Sundi, S. B. Mohamed, and I. S. Othman. "Investigation of surface topology in ball nose end milling process of Inconel 718." Wear 426 (2019): 1318-1326. https://doi.org/10.1016/j.wear.2018.12.076

[2] Mohammad, Ayad Z. "Study on Enhancing Mechanical Properties of Tin Bronze Alloy Using Laser Technique." INTERNATIONAL JOURNAL OF NANOELECTRONICS AND MATERIALS 11, no. 4 (2018): 411 418.

[3] Zheng, Pai, Zhiqian Sang, Ray Y. Zhong, Yongkui Liu, Chao Liu, Khamdi Mubarok, Shiqiang Yu, and Xun $\mathrm{Xu}$. "Smart manufacturing systems for Industry 4.0: Conceptual framework, scenarios, and future perspectives." Frontiers of Mechanical Engineering 13, no. 2 (2018): 137-150. https://doi.org/10.1007/s11465-018-0499-5

[4] Saeed, Fatima H., and K. Khalaf San'a. "Theoretical model for temperature distribution resulting from CW-Laser radiation heats up tumor tissues." (2019).

[5] Sheet, Melexis Data. "MLX90614 family, single and dual zone infrared thermometer in TO-39." (2009).

[6] Wang, Yanping, and Zongtao Chi. "System of wireless temperature and humidity monitoring based on Arduino Uno Platform." In 2016 Sixth International Conference on Instrumentation \& Measurement, Computer, Communication and Control (IMCCC), pp. 770-773. IEEE, 2016. 


\section{https://doi.org/10.1109/IMCCC.2016.89}

[7] Miah, Md Asaduzzaman, Mir Hussain Kabir, Md Siddiqur Rahman Tanveer, and M. A. H. Akhand. "Continuous heart rate and body temperature monitoring system using Arduino UNO and Android device." In 2015 2nd International Conference on Electrical Information and Communication Technologies (EICT), pp. 183-188. IEEE, 2015. https://doi.org/10.1109/EICT.2015.7391943

[8] Pawar, Prajakta A. "Heart rate monitoring system using IR base sensor \& Arduino Uno." In 2014 Conference on IT in Business, Industry and Government (CSIBIG), pp. 1-3. IEEE, 2014. https://doi.org/10.1109/CSIBIG.2014.7057005

[9] Priyadarshini, Indira, G. Jhansi, Nallamilli PG Bhavani, N. Jayachitra, V. Karthikeyan, K. S. Ram Kumar, and K. S. Kumar. "Clean coal technology using inventive materials for monitoring SO 2 emissions in smart power plants." AIPC 2105, no. 1 (2019): 020005.

[10] Shafi, Uferah, Rafia Mumtaz, José García-Nieto, Syed Ali Hassan, Syed Ali Raza Zaidi, and Naveed Iqbal. "Precision agriculture techniques and practices: From considerations to applications." Sensors 19, no. 17 (2019): 3796. https://doi.org/10.3390/s19173796

[11] Yang, Zhicheng, Parth H. Pathak, Mo Sha, Tingting Zhu, Junai Gan, Pengfei Hu, and Prasant Mohapatra. "On the feasibility of estimating soluble sugar content using millimeter-wave." In Proceedings of the International Conference on Internet of Things Design and Implementation, pp. 13-24. 2019. https://doi.org/10.1145/3302505.3310065

[12] Yang, Shunchang, Yikan Liu, Na Wu, Yingxiu Zhang, Spyros Svoronos, and Pratap Pullammanappallil. "Low-cost, Arduino-based, portable device for measurement of methane composition in biogas." Renewable Energy 138 (2019): 224-229. https://doi.org/10.1016/j.renene.2019.01.083

[13] Liebmann, F. "Uncertainty Budgets for IR Temperature Measurement-An Overview." Proceedings of Thermal Solutions (2008).

[14] T. Guide, "FLUKE Calibration," Fluke Corp., no. March, 2013.

[15] Jo, Byungwan, and Zafar Baloch. "Internet of things-based arduino intelligent monitoring and cluster analysis of seasonal variation in physicochemical parameters of Jungnangcheon, an urban stream." Water 9, no. 3 (2017): 220. https://doi.org/10.3390/w9030220 